\title{
Last Interview with Sir Michael Atiyah
}

John Alexander Cruz Morales (Universidad Nacional de Colombia, Bogotá, Colombia)

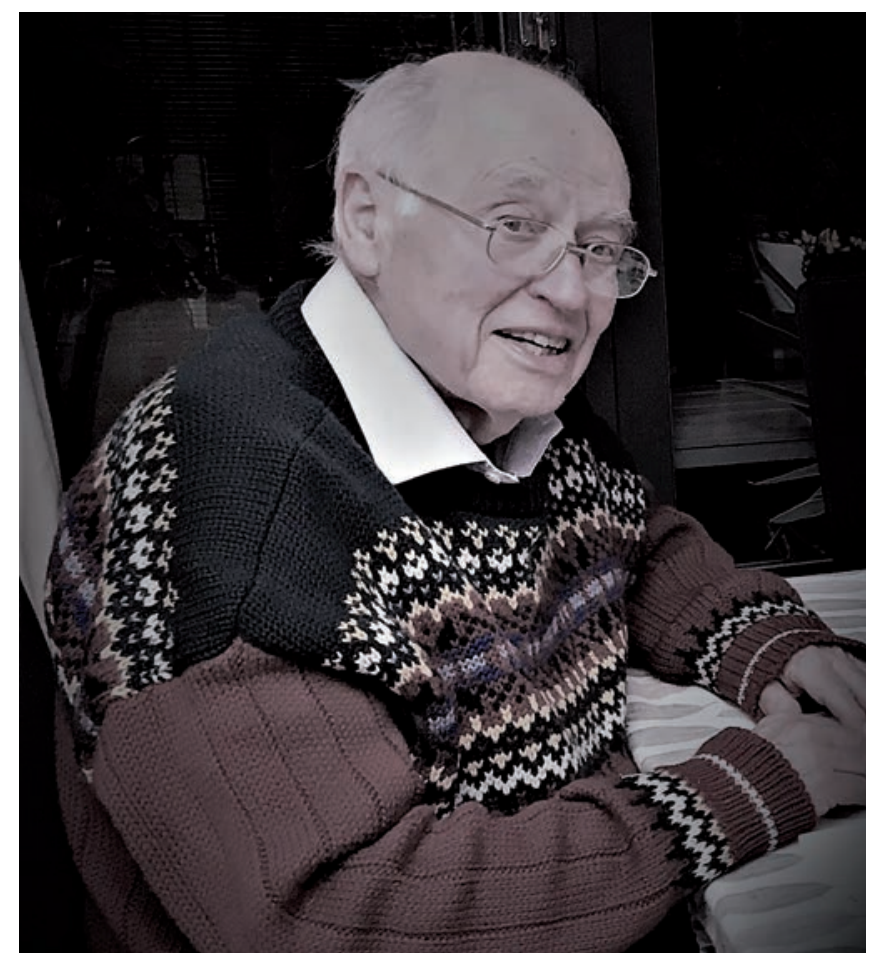

Last November I visited Edinburgh for one week, thanks to an invitation from Sir Michael Atiyah to discuss mathematical physics and, in particular, some of his latest projects and ideas. The weather, cold and rainy, was not the best for my taste but I really enjoyed walking around the city, going from my residence at the Glendale Guest House to Sir Michael's flat or his office at the School of Mathematics at the University of Edinburgh in order to get involved in a mathematical conversation with him. It was a wonderful week. We talked in the mornings, and then in the afternoons I received emails from Sir Michael summarizing our previous conversations and preparing the next one. We met every single day during my visit and the energy and enthusiasm Sir Michael showed will always be one of my best mathematical memories. I also gave a talk at the colloquium in the School of Mathematics thanks to Sir Michael's suggestion and I was able to appreciate again his sharp and deep mathematical insights in the form of comments on my presentation. The last day of my visit was December 1st and Sir Michael agreed to record our last conversation as an interview. That conversation is the one I am reproducing here. It was an informal and warm chat. This interview contains his last words to me, which I am sharing with the reader. After that, I got a couple of emails from him before receiving the sad news of his death and then this small interview gained more significance. I had already admired the mathematician but now, thanks to my visit, I also admire the man: a humble man full of generosity and kindness.
JACM: We have the dichotomy between inventing and discovering in mathematics. So, what do you think about this? Do we discover mathematics or invent mathematics?

MA: Mathematical truths are in our world. Our invention is to select from all the possible mathematical truths the ones that are really interesting. Now, how and why do we see that something is interesting? Because it is beautiful, it has a nice structure, it produces human emotion. A machine can not teach us to understand beauty. Newton said he was like somebody who goes to the beach and picks a nice pebble. There are million of pebbles on the beach but which one do you pick up? You pick up the ones that are nice, shiny and beautiful and thus you discover that pebble, you invent it. When you discover a mathematical truth you are inventing it because you find it and you choose one because it is more beautiful than the others. So, invention is selection. I select things that appeal to me. I am an artist. You have all the possible musical notes you can write. Why should I write some of those? There are million of possibilities of musical notes. Taking some is composing, is invention; we regard this as invention. All the possibilities are there. Inventing a symphony is a human creation. So, what is the difference in creating a beautiful piece of music and creating a beautiful mathematical theorem? I think it is the same.

When you think about mathematics, how do you choose a problem? What are your criteria for choosing a mathematical problem?

Well, everybody has their own criteria. Each mathematician has his own taste. But, of course, many mathematicians have the same views. Good mathematicians tend to appreciate each other even if they have different tastes. We choose a problem which we think it is interesting if it has features that appeal to us. It must be hard. You will see some beauty and some form emerging from it, like an artist. It must be deep; you can put a lot of adjectives but at the end it is difficult to describe. It is the decision of the individual artist or mathematician and that is personal. You can give a hundred of reasons but this does not define it completely. All you can do is to say that you view beauty in what you see. But, how to define beauty? How to define a good piece of mathematics? You can do it by illustrations. Poincaré duality is a beautiful piece of mathematics; you have to illustrate it by examples.

So, it is clear that beauty is an important criterion for you.

Absolutely! But we all have different kinds of beauties.

Who are the mathematicians that had an influence on your work? Who are your mathematical heroes? 
That is easy. From the past, Archimedes and Newton. In the more recent times Hermann Weyl was my hero. He had interests in everything in mathematics; he knew about beauty. Hermann Weyl is the mathematician that I have identified with most. Of course there are others. Poincaré I like very much and Abel who died very young. But Hermann Weyl is the closest one who had most influence on me.

Hermann Weyl was interested in the interactions between physics and mathematics like you. So, why is that interaction so important for you?

Until the 19th century nobody made a distinction. Was Newton a mathematician or a physicist? It is almost impossible to say. Newton was a great mathematician and a great physicist, no question. They did not distinguish. Later on mathematics became specialized; knowledge increased and then mathematics and physics seemed quite different, but that is not true. In physics there is a part to do with understanding experimental results and that is important science. Science has both experimental and theoretical sides. The theoretical side is like mathematics, the experimental side is different, but all mathematics is involved by taking things on experiments and making their understanding better by developing beautiful theories: Maxwell equations and so on. They are beautiful pieces of mathematics that showed to be very powerful in physics. All of physics has evolved by looking at all the data in experiments and then you find a simple way to organize it and that simple way of organizing is mathematics. It is ridiculous to separate mathematics and physics and it is also ridiculous to separate one knowledge from the other, for example to separate physics and chemistry or to separate physics and biology.

\section{In many places you have pointed out the importance of mathematical dreams. What is the role of the dreams in mathematics?}

Well, the main part of mathematics is to me not when you finish writing a proof , that is the last part. The main part is the initial ideas you want to develop. They are dreams. They may come at night when you are dreaming or during the day time; they are visions. You see the landscape, see some beautiful structure you do not know what it is going to be. You are dreaming when you are trying to capture some of this and then you have a plan. The proof of a theorem is not the beginning, it is the end. So, you start with a dream and end with a theorem. That is the natural process. Dreams are very important. Birkar, who got a Fields medal in Rio, said in his lecture that I told him once that a mathematician without a dream is not a mathematician. I think this is inspiring.

In fact, in your ICM lecture in Rio you talked about arithmetic physics as a research program. Might you summarise your vision regarding this program?

Yes. If you look at mathematics and physics they overlap in different areas; sometimes in geometry, sometimes in algebra, sometimes in number theory. For example, one very concrete case is the things called modular forms which arose in number theory. On the other hand, modular forms appear in physics as partition functions. Very often they are the same ones, and you wonder why. My aim is to find a natural framework which explains all this. There should be some natural way in which arithmetic, geometry, algebra and physics are all involved.

I appreciate a lot that you gave me some of your time for having this conversation. Let me make a final question. What would be your advice for a young mathematician?

My first advice for a young mathematician is that you have to be passionate. If you do it because you think you will get some money or you get a good job, forget it! There are easier ways to do that. And it is very hard work: you struggle and a lot of the time you are frustrated. The only way you succeed is if you are passionate. If you are passionate, then you will go a long way. The second thing is listen to your elders. Take their experience, but be your own person. Follow your own instinct because that way if you succeed, you will be unique. If you only follow what your teachers tell you, you will only repeat what they did. Listen to your teachers, go to lectures, read books; with that knowledge ask: what I want to do now. What you need is passion, persistence and risking things for searching for the beauty. If you do that, you have some chance to succeed. And do not be afraid to open your mind, talk to people. Interacting with other people, you get ideas. You need a balance between your passion and your family. You need a balanced life.

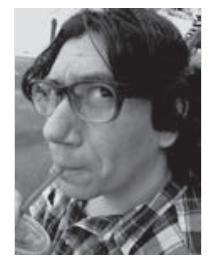

John Alexander Cruz Morales \{jacruzmo@ unal.edu.co] is a Colombian assistant professor in the mathematics department at Universidad Nacional de Colombia. His research interests are algebraic geometry and mathematical physics. He is also interested in the history and philosophy of mathematics. 